\title{
AquaBOL.SK - how far have we come with the Slovak reference barcode database since DNAqua- Net was launched?
}

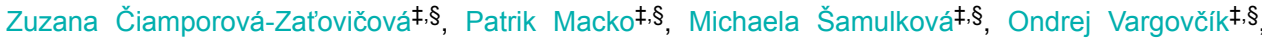 \\ Jana Bozáňováł,§, Fedor Čiampor Jrł
}

$\ddagger$ ZooLab, Plant Science and Biodiversity Centre, Slovak Academy of Sciences, Bratislava, Slovakia

$\S$ Department of Ecology, Faculty of Natural Sciences, Comenius University in Bratislava, Bratislava, Slovakia

Corresponding author: Zuzana Čiamporová-Zat'ovičová (zuzana.zatovicova@savba.sk)

Received: 24 Feb 2021 | Published: 04 Mar 2021

Citation: Čiamporová-Zatovičová Z, Macko P, Šamulková M, Vargovčík O, Bozáňová J, Čiampor Jr F (2021)

AquaBOL.SK - how far have we come with the Slovak reference barcode database since DNAqua-Net was

launched? ARPHA Conference Abstracts 4: e64939. https://doi.org/10.3897/aca.4.e64939

\section{Abstract}

Essential for implementation of molecular tools in bioassessments are comprehensive databases with high-quality reference DNA sequence data. A recent survey arising from the DNAqua-Net EU COST Action WG1 has revealed significant gaps in the barcode reference data of aquatic biota both on a taxonomic and a geographical level (Weigand 2019). Although reference barcode libraries of all main freshwater groups are continuously improved through a number of national DNA-barcoding campaigns, still little data is available from Central and Eastern Europe.

In Slovakia, the barcode coverage of the aquatic biota was very low when DNAqua-Net started. At the end of 2016 only 165 public records (60 OTUs) were available in BOLD ( $<3 \%$ of aquatic macroinvertebrates reported from Slovakia), and most of them were mined from GenBank. This led us to launch the campaign "Barcoding aquatic biota of Slovakia" (www.AquaBOL.SK), aiming to improve this unpleasant state. Since many common species in Slovakia are covered by barcodes from other countries, initially we focused on least explored habitat types within Europe - alpine glacial lakes in Tatra Mts and karstic springs. Both are located in Western and Slovak part of Eastern Carpathians, which are considered one of the most valuable biodiversity centers in Europe. 
More than 2700 sequences of COI-5P (337 BINs), originating in Slovakia, are currently in our dataset. Mostly they represent aquatic insects (86 \%) and crustaceans (12\%), followed by minor taxonomic groups. From insects, the best covered orders are Coleoptera $(43 \%$ of sequences, $21 \%$ of species), followed by Trichoptera (22\% of sequences, $24 \%$ of species) and Ephemeroptera (18\% of sequences, $33 \%$ of species). And even if other groups (Hemiptera, Plecoptera) represent only around $5 \%$ of all sequences each, their species coverage is already $21 \%$ or $28 \%$, respectively. Relatively high number of unique BINs (35 out of 337) from our area, and separate intraspecific lineages within BINs of many widespread species, supports the premise that the Western Carpathians belong to the most important biodiversity hotspots.

Our local reference database, continuously updated, is useful for the analysis and interpretation of metabarcoding data - a prerequisite for effective and nondestructive monitoring of aquatic biotopes including vulnerable, threatened, and protected habitats. It is also beneficial for a number of other purposes such as taxonomic revisions and phylogenetic analyses. This contribution was partially supported by VEGA2/0030/17, VEGA2/0084/2021 and COST CA15219.

\section{Keywords}

DNA barcoding, BOLD, freshwater biota, AquaBOL.SK, Slovakia

\section{Presenting author}

Zuzana Čiamporová-Zat’ovičová

\section{Presented at}

1st DNAQUA International Conference (March 9-11, 2021)

\section{References}

- Weigand $\mathrm{H}$, et al. (2019) DNA barcode reference libraries for the monitoring of aquatic biota in Europe: Gap-analysis and recommendations for future work. Science of the Total Environment 678: 499-52. 